The results (Table 2) show that the in vivo treatment of the host prolongs the survival of the skin homograft only if 'Urethan' is used at very high doses. The action of 'Urethan' in the experimental conditions reported here may be partly due to an antigenic simplification induced in vivo at the level of the grafted tissue.

It may be concluded that our experimonts suggest the possibility of attenuation of the reaction to homograft by means of a chemical antigenic deletion.

$$
\begin{aligned}
& \text { E. Bonmassar } \\
& \text { G. Francesconi } \\
& \text { S. C. Manzoni } \\
& \text { M. Perniti-ERcolini }
\end{aligned}
$$

Department of Pharmacology, University of Milan.

¿ Hitshingt, G. H., and Elion, G. B., Pharmacol. Hev., 15, 365 (1063).

'2 Bonmassar, E., and Mandruzzato, P., Areh. Ital. Pat. Clin. Tumori, 5, 407 (1962).

${ }^{3}$ Bonmassar, E., Melan, F., Prada, A., and Testorelli, F. (in the press).

- Bonmassar, E., di Roberto, F., and Mardi, E., Arch. Ital. Pat. Clin. Tumori 7,241 (1064).

- Bonmassar, E., Francesconi, G. Manzoni, S. C., and Perclli-Ercolini, M. Atti Accad. Med. Lomb., 19, $36 \%$ (1964).

'Francesconi, G., Frontino, G., and Perelli-Ereolini, M., Atti Accad. Med. Lomb., 16, 517 (1961).

' Cole, L. J., and Davis, W. E., Science, 135, 792 (1962).

\section{Immuno-adsorbents of High Capacity}

Preparation of antibodies is greatly fucilitated by the use of insoluble immuno-adsorbents. We have found that cross-linkage of soluble antigens with formaldehyde readily yields adsorbents having a high antibody capacity and which are insoluble over a wide rango of $p \mathrm{H}$. Most experiments have been carried out with an antigen (BSA-CPE) prepared by coupling the diazotized $p$-aminophenylether of choline (CPE; $\left.\mathrm{NH}_{2} \longrightarrow>\mathrm{OCH}_{2} \mathrm{CH}_{2} \stackrel{+}{\mathrm{N}}\left(\mathrm{CH}_{3}\right)_{3}\right)$ to bovine serum albumin ( $10 \mathrm{mols} / \mathrm{mole})$. An insoluble polymer of the BSA-CPE was prepared by slowly adding an equal volume of formaldehyde solution (40 per cent; $p \mathrm{H} 3 \cdot 1$ ) to a stirred 20 per cent solution of the antigen in $0.15 \mathrm{M}$ sodium ehloride. The reaction was allowed to proceed for $1 \mathrm{~h}$ at $25^{\circ} \mathrm{C}$ before the insoluble floceules of antigen polymer were separated by centrifuging. The floccules wero washed oxhaustively to remove excess formaldehyde with a solution containing $2 \mathrm{M}$ sodium chloride and $0.01 \mathrm{M}$ ammonium chloride adjusted to $p \mathrm{H}$ 9.0 with ammonium hydroxide, and finally with $0.15 \mathrm{M}$ sodium chloride.

Antibody was extracted from rabbit antisera $(1.5 \mathrm{mg}$ antibody $/ \mathrm{ml}$.) to $\mathrm{BSA}-\mathrm{CPE}$ by stirring $250 \mathrm{ml}$. serum $(p \mathrm{H} 7.0)$ with $1 \mathrm{~g}$ of the polymerized antigen for $30 \mathrm{~min}$ at $20^{\circ} \mathrm{C}$. The polymer was removed by centrifugation and washed with $0.15 \mathrm{M}$ sodium chloride $(p \mathrm{H} 7.0)$ until the washings contained less than $10 \mu \mathrm{g} / \mathrm{ml}$. protein. Washing was then continued with $2 \mathrm{M}$ sodium chloride. The antibody was dissociated from the insoluble antigen by the competitivo hapten choline $(2 \mathrm{M} ; p \mathrm{H} 7)$ by stirring with successive portions for $15 \mathrm{~min}$ at $25^{\circ} \mathrm{C}$. Choline was removed by passing through 'Sephadex $G-75$ ' equilibrated with $0.015 \mathrm{M}$ ammonium acetate. The choline. free antibody solutions were lyophilized and dissolved in a small volume of $0 \cdot 15 \mathrm{M}$ sodium chloride at $p \mathrm{H} 7 \cdot 0$. The small amount of insoluble protein was removed by centrifugation. The successive elutions by 25,50 and $50 \mathrm{ml}$. of choline chloride contained 103,47 and $15 \mathrm{mg}$ of protein respectively. The total yield of $165 \mathrm{mg}$ represented 71 per cent of the antibody extracted by the antigen polymer and an overall yicld of 47 per cent for tho single extraction. 'The purified antibody was 84 per cent precipitable by soluble BSA-CPE. Prolonging the time of contact between antiserum and the polymer increascd the overall yiold to 80 per cent. The capacity of the antigen polymer was about $300 \mathrm{mg}$ antibody/g. This capacity was somewhat lower than that of the cross-linked protein polymers prepared by Pressman et al. ${ }^{1}$.
This method has also been used successfully with other determinants, and polymerized BSA has been used to remove anti-BSA antibodies from sera. Dissociation in acid may be substituted for hapten compotition.

The method described horo would seem to offer a simple and general mothod for preparing highly purified antibodies against protein-linked determinants and may have a limited application in isolating antibodies to native proteins.

This work was supported by the Smith, Kline and French Foundation.

\section{J. C. Metcalfe}

H. F. Marlow

Departiment of Pharmacology, University of Cambridge.

'Onoue, K., Vagi, Y., and Pressman, D., Immunochemistry, 2, 181 (1965).

\section{Stimulation of Phagocytosis in Relation to the Mechanism of Action of Adjuvants}

ANTIGENS in emulsions of water-in-oil are known to enhance antibody response more effectively than when dissolved or suspended in saline ${ }^{1}$, but the mechanism of action of the adjuvant remains unsettled. Freund ${ }^{2}$ postulated that absorption, destruction and olimination of antigen are retarded by emulsions of water-in-oil with or without the presence of mycobacteria. Recently, however, Dresser ${ }^{3,4}$ found that subcutancous injection of Freund's adjuvant without antigen enhanced the antibody response against bovine $\gamma$-globulin given to mice intravenously: this suggests that the adjuvant exerts a nonspecific influence on the immune mechanism. Further, it has been demonstrated that Freund's adjuvant activates the immune machinery in the early phase of the primary immune response preceding the specific response against an antigen ${ }^{5}$. It has also been shown that phagocytosis of the antigen is a crucial step in the induction of the primary immune response $\theta^{8,7}$.

Recently we have found that oestrogens have an adjuvant effect on the primary immune response in mic ${ }^{8}$; and previously we have shown that stimulation of the reticulo-endothelial system by the administration of ocstrogen raises general body defence as indicated by increased phagocytic activity, raised serum $\gamma$-globulin, and increased protection of experimental animals against virulent infections ${ }^{\mathbf{9}}$. The present investigation has been designed to ascertain whether stimulation of the phagocytic activity of the reticulo-endothclial system is part of the mechanism of action of Freund's adjuvant.

Intact male white mice (T.O. Swiss strain) of $20-25 \mathrm{~g}$ body-weight were used throughout. Groups of five animals wore used to assess the effect on the reticuloendothelial system of each dose of adjuvant. Each animal received a subcutaneous or intraperitoneal injection (Table 1) of Freund's incomplete or complete adjuvant (Difco Laboratories) once daily for 3 days in the dosos shown. Phagocytic activity was assessed in these animals on the fourth day after treatment had started by measuring the rate of clearance of a known amount of a specially prepared carbon suspension from the circulating blood ${ }^{10}$. For each dose-response experiment five animals were used as controls; they received no treatment and were assessed by the carbon method on the same day as the treated animals. To investigate the speed of action and duration of effect of Freund's adjuvant on the reticulo-endothelial system (Table 2), groups of five animals received a single intraperitoneal injection of $0.2 \mathrm{ml}$. adjuvant; and on each successive day thereafter, up to the fourth day, phagocytic activity was assessed by the carbon method. Five untreated animals woro used daily as controls.

The results are shown in Tables 1 and 2 . The index of total-body phagocytic activity is denoted in the tables by the symbol $K$. The $K$ value indicates the rate of removal 